\title{
Measures of cognitive reserve in Alzheimer's disease
}

\author{
Medidas de reserva cognitiva na doença de Alzheimer
}

\author{
Margarida Sobral, ${ }^{1}$ Maria Helena Pestana,${ }^{2}$ Constança Paúl ${ }^{3}$
}

\section{Abstract}

Introduction: Cognitive reserve (CR), a hypothetical construct used to obtain information about cognitive aging, describes the capacity of the adult brain to cope with the effects of neurodegenerative processes. This study evaluated $C R$ using a CR questionnaire (CRQ) and a set of variables (education, leisure activities, lifelong occupation) that inform CR. It also developed a $C R$ index, validated the $C R Q$, and examined the correlation between the different CR measures.

Methods: Functional and neuropsychological capacities of 75 outpatients (mean age: 80.2 years) with a probable AD diagnosis were evaluated. Socio-demographic data and clinical variables were collected. Patients completed two questionnaires: the Participation in Leisure Activities throughout Life questionnaire, and the CRQ.

Results: Participants with a greater $\mathrm{CR}$ had higher scores in cognitive tests than the elderly with a lower CR. A CR index was developed. CRQ reliability was 0.795 (Cronbach's alpha). There was a close association between the CR Index and the CRQ.

Conclusions: This study found an association between $C R$ measures and education, occupation and participation in leisure activities. The CRQ seems to be a suitable instrument to measure $\mathrm{CR}$ in Portuguese populations.

Keywords: Alzheimer's disease, cognitive reserve, education, leisure activities, lifelong occupation, Cognitive Reserve Index, Cognitive Reserve Questionnaire.
\end{abstract}

\section{Resumo}

Introdução: A reserva cognitiva ( $R C$ ), um construto usado para informar sobre o envelhecimento cognitivo, descreve a capacidade do cérebro adulto em lidar com os efeitos de processos neurodegenerativos. Este estudo teve como objetivos avaliar a RC com o Questionário de RC (QRC) e através de variáveis (escolaridade, actividades de lazer, ocupação ao longo da vida) que informam sobre a RC; desenvolver um índice de RC; validar o QRC; e correlacionar as diferentes medidas de RC. Métodos: Foram avaliadas as capacidades funcionais e neuropsicológicas de 75 doentes (idade média: 80,2 anos) com diagnóstico de provável doença de Alzheimer, seguidos em ambulatório. Os dados recolhidos incluíram variáveis sócio-demográficas e clínicas. Os pacientes completaram dois questionários: Participação em Atividades de Lazer ao Longo da Vida; e QCR.

Resultados: Os doentes com os níveis mais elevados de RC obtiveram os valores mais elevados nos testes cognitivos. Neste estudo foi desenvolvido um IRC. O QRC (versão portuguesa) teve uma fidelidade de 0,795 (alpha de Cronbach) e foi demonstrada uma associação alta entre o IRC e o QRC.

Conclusões: Verificou-se a existência de uma associação entre as medidas de RC e a escolaridade, ocupação e participação em atividades de lazer. O CRQ pode ser considerado um instrumento adequado para medir o CR da população portuguesa.

Descritores: Doença de Alzheimer, reserva cognitiva, escolaridade, atividades de lazer, ocupação ao longo da vida, Índice de Reserva Cognitiva, Questionário de Reserva Cognitiva.

\footnotetext{
${ }_{1}^{1}$ Psychogeriatric Service, Hospital Magalhães Lemos, Porto, Portugal. Unidade de Investigação e Formação sobre Adultos e Idosos (UNIFAI), Instituto de Ciências Biomédicas Abel Salazar (ICBAS), Universidade do Porto, Porto, Portugal. ${ }^{2}$ UNIFAI, ICBAS, Universidade do Porto, Porto, Portugal. Instituto Universitário de Lisboa (ISCTE-IUL), Lisbon, Portugal. ${ }^{3}$ UNIFAI, ICBAS, Universidade do Porto, Porto, Portugal.

Financial support: none.

Submitted May 07 2014, accepted for publication Jul 10 2014. No conflicts of interest declared concerning the publication of this article.

Suggested citation: Sobral M, Pestana MH, Paúl C. Measures of cognitive reserve in Alzheimer's disease. Trends Psychiatry Psychother. 2014;36(3):160-168. http://dx.doi.org/10.1590/2237-6089-2014-0012
} 


\section{Introduction}

Alzheimer's disease ( $A D)$, the most common form of dementia among the elderly, ${ }^{1,2}$ is a progressive neurodegenerative disorder characterized by deterioration of cognitive and functional capacities and a number of neuropsychiatric and behavioral symptoms. ${ }^{3}$ The risk of dementia grows exponentially with age. ${ }^{4}$ In 1988, a study reported that 10 cognitively healthy elderly women had pathological features of Alzheimer's disease, confirmed by plaques found at autopsy. ${ }^{5}$

Cognitive reserve (CR), a hypothetical construct that provides information about cognitive aging, describes the capacity of the adult brain to cope with the effects of neurodegenerative processes and to minimize the clinical signs of dementia. CR may result from innate intelligence or life experiences. ${ }^{6}$ The CR hypothesis suggests that individual differences in the ability to cope with $A D^{6,7}$ are consistent with the prediction that people with a greater CR cope with advancing AD longer before the disease is observed clinically. ${ }^{7-9} \mathrm{CR}$ is not fixed, and continues to evolve across the lifespan. ${ }^{9}$ The major barrier to studying CR lies in its measurement. ${ }^{10,11}$ As a hypothetical construct, $\mathrm{CR}$ is not measured directly. Variables pertaining to lifetime experience, such as education, occupation and leisure activities, all of which help to retain cognitive function in old age, are the most commonly used proxies for CR.

According to Albert et al., ${ }^{12}$ persons with a higher educational attainment show less cognitive decline with advancing age, and other studies showed that persons with a higher education perform better in cognitive tests. ${ }^{13}$ James et al. ${ }^{14}$ showed that more socially active older adults experience less cognitive decline in old age. A greater understanding of the concept of CR may lead to interventions to slow cognitive aging. ${ }^{8}$ Sobral \& Paúl ${ }^{15}$ demonstrated that patients with $A D$ and higher levels of education achieved better results in cognitive tests, and that individuals with greater participation in leisure activities (PLA) had better results in cognitive and functional tests than those with a lower participation.

The risk of developing $A D$ is reduced in individuals with a higher education, ${ }^{8}$ greater occupational attainment $^{8}$ and PLA. $8,16,17$ Other studies found no association between education and incident dementia ${ }^{18}$ and no association between occupation and incident $A D$ in several population-based longitudinal studies. ${ }^{19}$

The objectives of this study were: 1 ) to assess CR using a $C R$ questionnaire (CRQ) and a set of variables (education, leisure activities, lifelong occupation) that inform $C R ; 2$ ) to develop a CR index; 3) to validate the CRQ; and 4) to examine the correlation between different measures of $C R$ (CRQ, CR index, education, PLA and lifelong occupation).

\section{Methods}

\section{Participants}

This study included 75 outpatients (mean age: 80.2 years; range: 61-92 years) diagnosed with probable $A D$, recruited by convenience at the psychogeriatric service of a psychiatric hospital. This psychogeriatric service is designed to follow up patients with dementia, using an integrated multidisciplinary approach to diagnosing and managing dementia. Physical, neurological, neuropsychological and psychiatric examinations, neuroimaging and additional tests, including blood tests, were used to distinguish between the various types of dementia. All patients fulfilled the criteria of both the Diagnostic and Statistical Manual of Mental Disorders, 4th edition (DSM-IV) ${ }^{20}$ and the National Institute for Neurological and Communicating Disorders and Stroke/AD and Related Disorders Association for probable AD. ${ }^{21}$ The participants had no severe medical conditions other than those pertinent to the study. They all had normal or corrected levels of hearing and vision acuity. The patients, their caregivers or their legal guardians signed a written consent form.

Mean age ( \pm standard deviation) was $80.20 \pm 5.64$ years, and mean educational level was 5.45 years. Table 1 shows the demographic and clinical characteristics of participants with AD.

There were significantly more women than men (binomial test; $\mathrm{p}<0.001$ ). The age difference between sexes was not statistically significant ( $t$ test; $p=0.3$ ). There were more married men $(80.5 \%)$ than married women (30.9\%) (Likelihood ratio; $p<0.001$ ), but differences in other marital statuses were not relevant $(p=0.6, L R)$. Women had very different levels of education. The mean of 5.75 years of education was replaced with a trimmed mean of $5 \%$ ( $5 \%$ trimmed mean $=5.45)$, and the standard deviation was replaced with the interquartile range (Tukey's hinges): $50 \%$ of the men had 4 to 10 years of education, whereas $50 \%$ of the women had 3 to 4.5 years. Men had a mean 2.63 more years of education than women. At each higher educational level, there was a $13 \%$ greater likelihood to find men than women, according to the binary logistic regression model and good sampling adequacy (Hosmer and Lemeshow test $=1.73$; $\mathrm{df}=$ $4 ; p=0.79)$ and $\operatorname{Exp}(\mathrm{sex})=1.13$. The presence of unskilled women $(70.9 \%)$ was more likely than that of unskilled men $(20 \%)$ (LR; $p<0.001)$, but differences in the other work status categories were not significant $(L R ; p=0.4)$. 
Table 1 - Demographic and clinical characteristics

\begin{tabular}{|c|c|c|}
\hline Characteristics & Patients with AD $(n=75)$ & Tests (p) \\
\hline Men $<$ women & $26.7(20)<73.3(55)$ & Binomial $(p<0.001)$ \\
\hline Age, mean \pm SD (min-max) & $80.20 \pm 5.64(61-92)$ & $t$ test $(p=0.3)$ \\
\hline \multicolumn{3}{|l|}{ Marital status } \\
\hline Married: men > women & 45.3 (34): $85 \%>30.9 \%$ & LR $(p<0.001)$ \\
\hline Widowed & $38.7(29)$ & $\operatorname{LR}(p=0.6)$ \\
\hline Single & $10.7(8)$ & $\operatorname{LR}(p=0.6)$ \\
\hline Divorced & $5.3(4)$ & $\operatorname{LR}(p=0.6)$ \\
\hline \multicolumn{3}{|l|}{ Educational level } \\
\hline \multirow{3}{*}{$\begin{array}{l}5 \% \text { trimmed mean }(\mathrm{IR})(\min / \mathrm{max}) \\
\text { men }>\text { women }\end{array}$} & $5.45(3-9)(0-17):$ & \\
\hline & $7.39(4-10)(2-17)>$ & $t$ test $(p=0.025)$ \\
\hline & $4.76(3-4.5)(0-16)$ & \\
\hline Illiterate & $6.7(5)$ & Chi-square and omnibus Wald test \\
\hline Reading and writing & $22.7(17)$ & \\
\hline 4 years & $41.3(31)$ & $\begin{array}{l}\operatorname{Exp}(\operatorname{sex})=1.13 \\
\quad(p=0.04)\end{array}$ \\
\hline$>4-9$ years & $16.0(12)$ & \\
\hline$\geq 11$ years & $13.4(10)$ & \\
\hline Portuguese nationality & $100(75)$ & \\
\hline \multicolumn{3}{|l|}{ Work status } \\
\hline Retired & $96(72)$ & \\
\hline Unskilled worker: men < women & $57.3(43): 20 \%<70.9 \%$ & LR $(p<0.001)$ \\
\hline Skilled worker & $10.7(8)$ & $\operatorname{LR}(p=0.4)$ \\
\hline $\begin{array}{l}\text { Service worker, safety worker, vendors and } \\
\text { administrative staff }\end{array}$ & $24.0(18)$ & $\operatorname{LR}(p=0.4)$ \\
\hline $\begin{array}{l}\text { Intermediate level occupation, intellectual } \\
\text { and scientific activity }\end{array}$ & $8.0(6)$ & $\operatorname{LR}(p=0.4)$ \\
\hline Years of disease, mean \pm SD $(\min -\max )$ & $5.17 \pm 3.31(1-13)$ & $t$ test $(p=0.223)$ \\
\hline Social class (Graffar) & & $\operatorname{LR}(p=0.241)$ \\
\hline II (medium/high) & $10.7(8)$ & \\
\hline III (medium) & $42.7(32)$ & \\
\hline IV (medium/low) and V (low) & $46.7(35)$ & \\
\hline Lives alone & & Fisher's test $(p=0.327)$ \\
\hline Yes & $20.0(15)$ & \\
\hline No & $80.0(60)$ & \\
\hline $\begin{array}{l}\text { Does not live with wife/husband: } \\
\text { men }<\text { women }\end{array}$ & $56.0(42): 25(5)<67.3(37)$ & Fisher's test $(p=0.002)$ \\
\hline Attends day care & & Pearson's chi-square, $(p=0.739)$ \\
\hline Yes & $22.7(17)$ & \\
\hline No & $77.3(58)$ & \\
\hline \multicolumn{3}{|l|}{ Lives in a nursing home } \\
\hline Yes & $1.3(1)$ & \\
\hline No & $98.7(74)$ & \\
\hline \multicolumn{3}{|l|}{ Has a caregiver } \\
\hline Yes & $94.7(71)$ & \\
\hline No & $5.38(4)$ & \\
\hline $\mathrm{CDR}=1$ & $46.7(35)$ & $\operatorname{LR}(p=0.463)$ \\
\hline $\mathrm{CDR}=2$ & $36.0(27)$ & \\
\hline$C D R=3$ & $17.3(13)$ & \\
\hline
\end{tabular}

Results expressed as \% (n), unless otherwise stated.

$\mathrm{AD}=$ Alzheimer's disease; $C D R=$ Clinical Dementia Rating; $\operatorname{Exp}(B)=$ odds ratio; $I R=$ interquartile range; $L R=$ chi-square likelihood ratio test; $\mathrm{SD}=$ standard deviation . 


\section{Instruments}

The $\mathrm{CRQ}^{22}$ was administered to measure CR. The contribution of factors such as activities (reading, intellectual games), years of education, years of parents' education, occupation, training courses, musical training and language studies of participants during their adult lifetime were included to calculate CR. The CRQ has eight items with several different possible answers.

Data about PLA was obtained from a questionnaire, the Participation in Leisure Activities throughout Life, answered by the participants or their caregivers. ${ }^{15}$ Most were completed by the participant with the help of the caregiver. This questionnaire was limited to the assessment of leisure activities throughout life and not current activities (after onset of disease). This tool included mental activities (reading books/ newspapers, jigsaw puzzles), physical activities (walking or sports), social activities (playing cards/ board games, visiting friends or relatives), productive activities (housekeeping, babysitting, gardening, crocheting) and recreational activities (listening to the radio, watching television). Participants reported the frequency of PLA throughout life as daily, several days per week, once a week, two or three days a month, monthly, and never or less than once a month. They were asked whether they engaged regularly in other specific activities, and all had to specify which activities and the frequency of PLA throughout life. The instrument produced a total score and classified people in three categories: low, medium and high PLA throughout life. The PLA throughout life questionnaire has 17 questions; in each question, 5 points were added if the frequency was daily, 4 , if several days per week, 3, if once a week, 2, if two or three days per month, 1 , if monthly and 0 , if less than once a month or never. Total scores ranged from 0 to 85 points.

All participants were given the Mini Mental State Examination (MMSE) ${ }^{23}$ for cognitive screening and the Clinical Dementia Rating (CDR). We used the Portuguese version of the MMSE. ${ }^{24}$ The normative cut-off values were adjusted to education level for a Portuguese population. The cut-off points for the diagnosis of dementia were greater than 27 if the participant had $>11$ years of education, $\leq 22$ if they had 1-11 years of education, and $\leq 15$ if they were illiterate. The $\mathrm{CDR}^{25}$ classifies dementia into 3 stages of severity as a function of overall cognitive and functional impairment and determines the impairment associated with dementia using parameters such as memory, orientation, judgment and problem solving, community affairs, home and hobbies and personal care. The overall CDR score was obtained using a standard algorithm to stage the patient's level of impairment: 0 , no impairment; 0.5 , very mild impairment; 1, mild dementia; 2, moderate dementia; and 3, severe dementia. The scale was administered to the patients and an informant using a semi-structured interview. The Addenbrooke's Cognitive Examination Revised (ACE-R) ${ }^{26}$ is a brief cognitive test that assesses five cognitive domains, namely: attention/orientation, memory, verbal fluency, language and visuospatial abilities. The total score is 100 , and higher scores indicate better cognitive functioning.

Functional capacities were assessed using two scales of activities of daily living: the Barthel's Index (BI), for basic activities of daily living, such as grooming, eating, bathing, dressing and mobility; and the Lawton \& Brody's Index (LBI), for instrumental activities, such as managing money and using the telephone. The BI total score may range from 0 to 100 (fully independent) and the LBI, from 8 (independent) to 30 (completely dependent).

Socioeconomic status was evaluated according to the Graffar Index. ${ }^{27}$ This index has five categories, from I (very low) to V (very high). Lifelong occupation was assessed using the National Classification of Occupations. ${ }^{28}$

\section{Procedures and statistical design}

This cross-sectional study retrieved data from the database of a larger study to investigate Dementia and Cognitive Reserve (DCR) in patients recruited at Hospital Magalhães Lemos, Porto, Portugal. This study was approved by the Review Board (ethics committee) of the institution where it was conducted. Socio-demographic and clinical variables (age, gender, marital status and retirement status), as well as variables that usually inform CR (education level, lifelong occupation and frequency of PLA), were collected. Each participant underwent a standard evaluation, including medical history, physical examination, laboratory tests and a neuroimaging study (axial CT). All patients with AD were evaluated using MMSE and $C D R$ at a first consultation for a multidisciplinary assessment before recruitment. Participants underwent functional and neuropsychological evaluations, and specific neuropsychological domains were examined: memory, language, attention, visuospatial ability and executive functioning.

According to the hypothesis of this study, the following variables may affect CR: CRQ score, Cognitive Reserve Index (CRI), level of educational attainment, PLA score and lifelong occupation.

General exploratory analyses were conducted to determine sample characteristics. Means, standard 
deviations, interquartile ranges and percentiles were used for descriptive statistics. Logistic regression and the Student $t$ test were used to infer the relationship between metric and binary response data; multinomial regression and analysis of variance (ANOVA) were used when the response variable had more than two categories. Contingency tables were prepared to examine the association between categorical variables whenever odds ratio (OR), the Pearson chi-square test, the Fisher exact test, likelihood ratios and Cochran's statistics did not reveal any interactive effects. ${ }^{29}$

Factorial analysis of principal components and the Kaiser-Meyer-Olkin and Bartlett's test of sphericity were used to test CRQ construct validity and the underlying dimension of CR. CRQ reliability was assessed using Cronbach's alpha, which measures internal consistency and indicates to what degree the instrument produces consistent results or equivalents.

A CR index (CRI) was developed and tested in our sample. An index is a latent variable that summarizes the group of correlated variables to simplify their interpretation. To create the CRI, we selected variables that are measures of CR (education, PLA and lifelong occupation) according to the literature and tested them for homogeneity of variance. An equation was used to standardize these variables. This CRI was composed of the following CR variables: education (illiterate, reading and writing, $=4$ years, $>4$ years), PLA ( $\leq$ $25,26-35, \geq 36$ ) and lifelong occupation (unskilled worker, skilled worker, service worker, safety worker, vendor and administrative staff, intermediate level occupation, intellectual and scientific activity). These variables were scored using different scales, and we defined an equation of linear transformation when minimum and maximum values were not symmetrical to the mean. The new 0 -to-10 scale was constructed using the expression below:

Cognitive Reserve Index $=$ Cognitive Reserve Index_construction x $5 \times(1.63+1.29) /[$ Cognitive Reserve Index_construction $\times(1.63-1.29)-2 \times(-1.29$ $x$ 1.63) $]+5$

This linear equation is given by the following transformation:

$$
t=\frac{1}{\mathrm{~m} \times z+c}+b=\frac{5 z \times(\max -\min )}{z \times(\min +\max )-2 \times \min x \max }+5
$$

Where:

$$
\begin{aligned}
& m=\frac{\min +\max }{5(\max -\min )} ; c=\frac{2 \times \min x \max }{5 \times(\min -\max )} ; b=5 \\
& z=\text { represents the standardized variables }
\end{aligned}
$$

The analyses were conducted using the IBM Statistical Package for the Social Sciences (SPSS) version 21.

\section{Results}

The cognitive assessment revealed that patients with $A D$ had a low level of CR (CRQ), and their mean scores were 16.25 on MMSE, 37.96 on ACE-R, 9.24 in attention and orientation (ACE-R), 4.51 in memory (ACE-R), 2.35 in fluency (ACE-R), 14.53 in language (ACE-R) and 7.53 on the visuospatial test (ACE-R), whereas patients with $A D$ and a medium and high level of CR (CRQ) had a mean score of 19.79 on MMSE, 52.05 on ACE-R, 10.89 in attention and orientation (ACE-R), 6.82 in memory $(A C E-R), 3.65$ in fluency (ACE-R), 19.59 in language $(A C E-R)$, and 10.18 on the visuospatial test (ACE-R). The participants with higher $C R$ levels had higher scores on cognitive tests than the elderly with lower CR levels.

The results of functional tests revealed that mean BI was 86.67, and mean LBI, 23.36. Mean BI of patients with $A D$ and a low CR (CRQ) was 87.23, and LBI, 23.66. Mean BI of patients with $A D$ and a medium or high $C R$ (CRQ) was 85.00, and LBI, 22.47.

\section{Association between CR (CRQ and CRI) and education, participation in leisure activities and lifelong occupation}

Mean CRQ score was 5.53, and mean CRI was 4.85. Pearson's correlation $(r=0.674)$ and Spearman's rho correlation ( $r=0.645)$ were significant at a level of significance of 0.01 (2-tailed) when comparing CRQ and CRI. Participants with a higher CRI had the highest CRQ scores.

Significant results at a level of 0.01 (2-tailed) were found for Pearson's correlation ( $r=0.604)$ and Spearman's rho correlation $(r=0.645)$ between CRQ and education; Pearson's correlation $(r=0.306)$ and Spearman's rho correlation ( $r=0.340$ ) between CRQ and PLA; and Pearson's correlation ( $r=0.621)$ and Spearman's rho correlation ( $r$ $=0.589$ ) between CRQ and lifelong occupation. Patients with $A D$ and a higher educational level had higher $C R Q$ scores than those with a lower educational level. Patients with a higher PLA score had higher CRQ scores than those with a lower level of PLA. Participants that had complex occupations had higher CRQ scores than patients with less complex occupations. Significant results at a level of 0.01 (2-tailed) were found for Pearson's correlation $(r=0.864)$ and Spearman's rho correlation $(r=0.883)$ between CRI and education; Pearson's correlation $(r=0.633)$ and Spearman's rho correlation ( $r=0.648)$ between CRI and PLA; and, Pearson's correlation ( $r=0.713)$ and Spearman's rho correlation $(r=0.662)$ between CRI and lifelong occupation. Patients with AD and a higher educational level had a higher CRI. Patients with higher PLA scores had a higher CRI. Participants with more complex occupations had a higher CRI. 
A

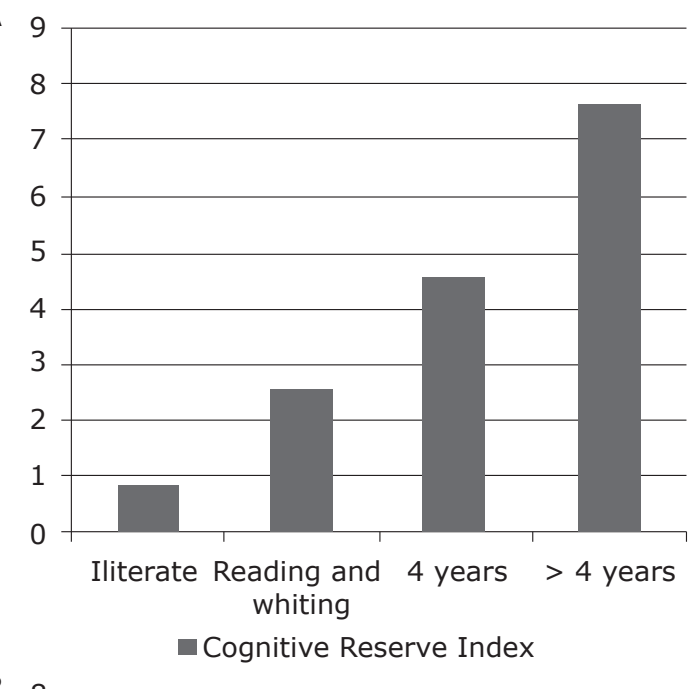

B

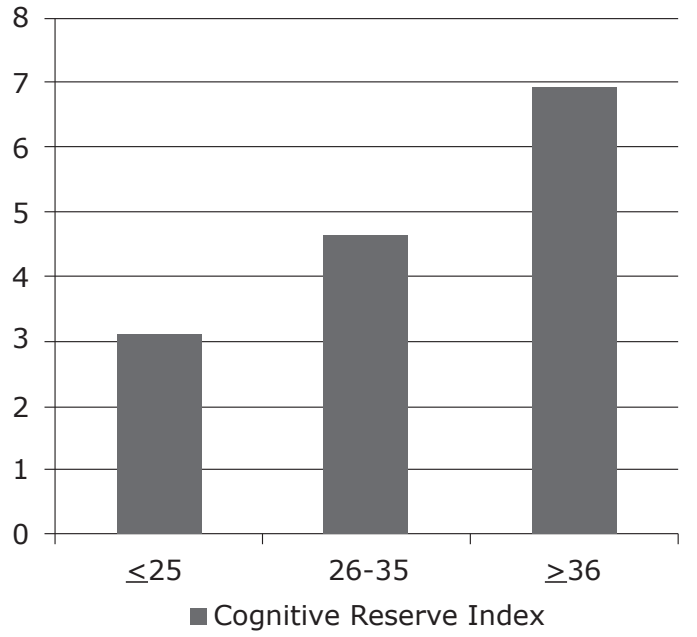

C

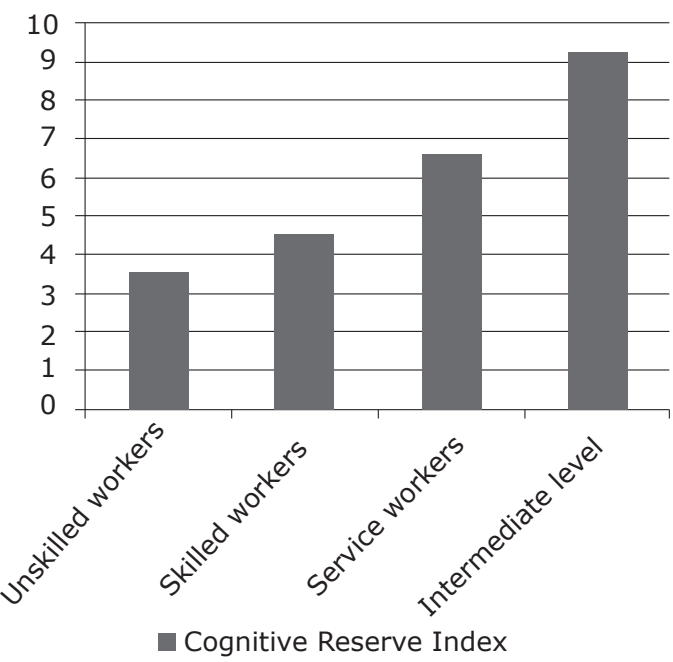

Figure 1 - Cognitive Reserve Index compared with: A) education (illiterate, reading and writing, 4 years, $>4$ years); B) participation in leisure activities (PLA) $(\leq 25$, 26-35, $\geq 36$ scores); and C) lifelong occupation (unskilled worker, skilled worker, service worker, safety worker, vendor and administrative staff, intermediate level occupations, intellectual and scientific activity).
The analysis of CRI according to educational level (Figure $1 \mathrm{~A}$ ) revealed that the $>4$ years group had the highest CRI; mean CRI in the illiterate group was 0.83 , in the reading and writing group, 2.57 , in the $=4$ years group, 4.55 , and in the $>4$ years group, 9.67. There were significant differences in CRI between the levels of education $\left(t_{(3)}=77.61 ; p<0.001\right)$. In this study, we found that the patients with a higher educational level had a greater CR according to CRI.

The patterns of CRI for different PLA levels (Figure 1B) showed that the $\geq 36$ group had the highest CRI. Mean CRI for the group with $\leq 25$ scores was 3.10 , for the group with $26-35$ scores, 4.63 , and for the group with $\geq$ 36 scores, 6.93 . There were significant differences in CRI between PLA levels $\left(t_{(2)}=17.88 ; p<0.001\right)$. Patients with higher PLA scores had a greater CR according to CRI than the patients with lower PLA scores.

The patterns of CRI for different lifelong occupations (Figure 1C) showed that the group of participants with intermediate level occupations and intellectual and scientific activity had the highest CRI. For unskilled workers, mean CRI was 3.54; for skilled workers, 4.53 , for service workers, safety worker, vendors and administrative staff, 6.64, and for intermediate level occupations and individuals that work with intellectual and scientific activity, 9.23. There were significant differences in CRI between lifelong occupation groups $\left(t_{(3)}=25.94 ; \mathrm{p}=0.000\right)$. Patients with more complex occupations had a higher CR according to CRI than patients with less complex occupations.

The patterns of CRQ scores for different educational levels (Figure 2A) showed that individuals with more than four years of education ( $>4$ years) had the highest scores. Mean CRQ scores for the group of illiterate individuals was 1.00 , for the reading and writing group, 2.85 , for the $=4$ years group, 4.48 , and for the $>4$ years group, 9.67. There were significant differences in CRQ scores between educational levels $\left(t_{(3)}=18.36 ; \mathrm{p}\right.$ $=0.000$ ). Patients with higher educational levels had a greater CR according to CRQ scores than the patients with a lower educational level

The analysis of CRQ scores for different PLA levels (Figure $2 \mathrm{~B}$ ) revealed that the $\geq 36$ group had the highest scores. The group with $\leq 25$ scores had a mean 4.29 CRI, the group with 26-35 scores had a mean of 4.97, and the group with $\geq 36$ scores had a mean of 6.67. There were significant differences in CRQ scores between PLA levels $\left(t_{(2)}=3.58 ; \mathrm{p}=0.033\right)$. Patients with higher PLA scores had a greater CR according to CRQ than patients with a lower PLA score.

CRQ scores for groups of individuals with different lifelong occupations (Figure 2C) showed that the groups with intermediate level occupations and intellectual and 
scientific activities had the highest CRQ scores. The group of unskilled workers had a mean 3.37 CRQ score, the group of skilled workers, a mean of 5.00, the group of service workers, safety workers, vendors and administrative staff, a mean of 8.00, and the group of individuals with intermediate level occupations and intellectual and scientific activity, a mean of 14.33 . There were significant differences in CRQ score between the groups of lifelong occupations $\left(t_{(3)}=25.35 ; \mathrm{p}=0.000\right)$. Patients with more complex occupations had a greater CR according to CRQ scores than patients with less complex occupations.

\section{Validation of the Cognitive Reserve Questionnaire}

Two independent translations were made from Spanish into Portuguese, followed by two independent back-translations. Some adaptations to linguistic and cultural aspects of Portuguese individuals were made, and a first version was produced.

CRQ construct validity of the underlying CR dimension was analyzed using factorial analysis of principal components, and internal consistency was assessed using Cronbach's alpha.

In the analysis of construct validity, factorial analysis of principal components with varimax rotation adapted well to data and was a good indicator of the quality of the adjustment obtained by goodness of fit (index $=0.99$ ) and by root mean square residual $(0.048)$, which were based on the residual matrix correlation. The existence of an eigenvalue $>1$ (Kaiser criterion) and the steepening of the scree plot indicated the existence of a single dimension in CR. Responses were consistent, because there was a good correlation between items according to the measure of sampling adequacy (Kaiser-Meyer-Olkin $=0.761$; Bartlett's sphericity test $=204.159 ; \mathrm{df}=28 ; \mathrm{p}<0.01$ ) .

The reliability of the 8-item Portuguese version of the CRQ had good internal consistency (Cronbach's alpha = 0.795 ), similar to that found in the original CRQ study. ${ }^{21}$ Table 2 shows the results of statistics for CRQ items.

Musical training had the lowest correlation with the other items due to weak variability in responses, as $97.3 \%$ reported not playing or listening to music (Table 3 ).

We found that the values of alpha with and without any item were close, which showed that the CRQ was not dependent on any particular item. This confirmed that all matters relating to the $\mathrm{CR}$ are relevant.

Figure 3 shows that the higher the mean value of CRI, the greater the CR according to CRQ scores. Moreover, higher CRI results are followed by a greater likelihood of patients having an average or great $\mathrm{CR}$, represented by CRQ scores, according to the $F$ test as one-way ANOVA $(F=60.638 ; p<0.001)$.
A

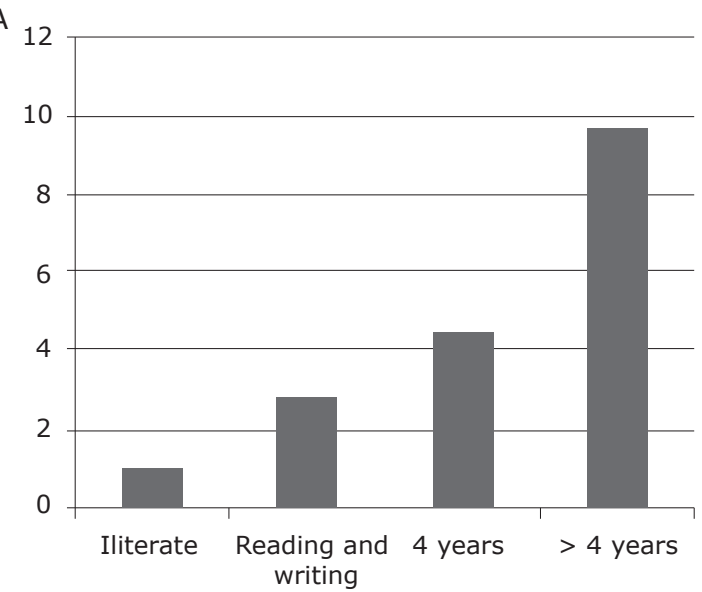

B

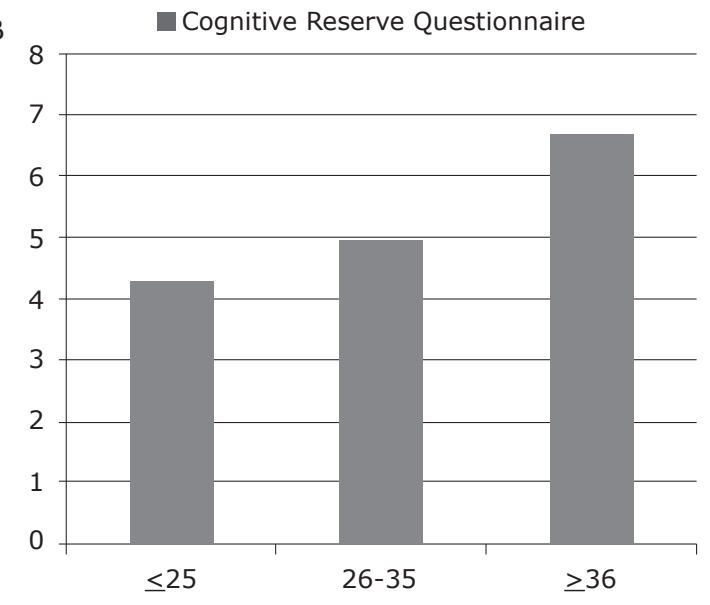

- Cognitive Reserve Questionnaire

C

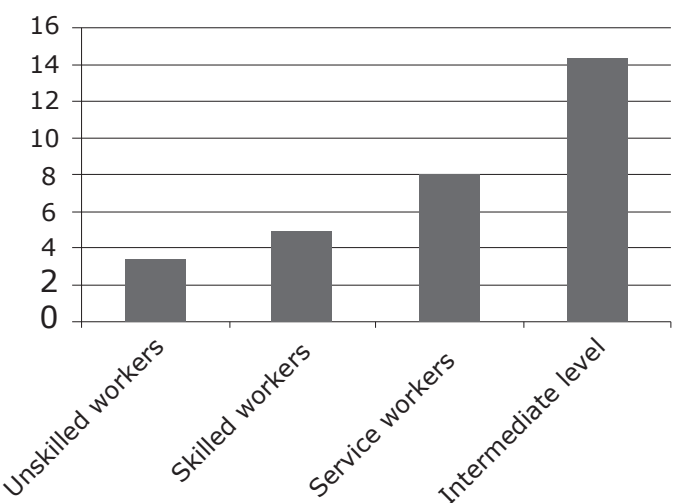

Cognitive Reserve Questionnaire

Figure 2 - Cognitive Reserve Questionnaire scores compared with $\mathrm{A}$ ) education (Illiterate, reading and writing, $=4$ years,

$>4$ years $) ; B$ ) participation in leisure activities $(\leq 25$,

26-35, $\geq 36$ scores); and C) lifelong occupation (unskilled worker, skilled worker, service worker, safety worker, vendor and administrative staff, intermediate level occupation, intellectual and scientific activity).

We demonstrated a close association between CRI and CRQ (eta $=0.674$ ), which corroborates the validity of the cognitive reserve construct. We found that $45.4 \%$ of the variation of CRI was determined by CRQ scores, and that $45.4 \%$ of the variation of CRQ score was determined by CRI. 
Table 2 - Items-total statistics

\begin{tabular}{lccccc}
\hline & $\begin{array}{c}\text { Scale mean if } \\
\text { item deleted }\end{array}$ & $\begin{array}{c}\text { Scale variance } \\
\text { if item deleted }\end{array}$ & $\begin{array}{c}\text { Corrected item-total } \\
\text { correlation }\end{array}$ & $\begin{array}{c}\text { Squared multiple } \\
\text { correlation }\end{array}$ & $\begin{array}{c}\text { Cronbach's alpha } \\
\text { if item deleted }\end{array}$ \\
\hline $\begin{array}{l}\text { Education } \\
\begin{array}{l}\text { Parental } \\
\text { education }\end{array}\end{array}$ & 2.95 & 8.107 & 0.769 & 0.649 & 0.733 \\
$\begin{array}{l}\text { Training } \\
\text { courses }\end{array}$ & 4.50 & 13.788 & 0.452 & 0.284 & 0.783 \\
$\begin{array}{l}\text { Occupation } \\
\begin{array}{l}\text { Musical } \\
\text { training }\end{array}\end{array}$ & 5.15 & 12.265 & 0.632 & 0.529 & 0.755 \\
$\begin{array}{l}\text { Languages } \\
\text { Reading }\end{array}$ & 5.38 & 9.494 & 0.755 & & 0.674 \\
$\begin{array}{l}\text { Intellectual } \\
\text { games }\end{array}$ & 5.00 & 15.718 & -0.055 & 0.029 & 0.723 \\
\hline
\end{tabular}

Table 3 - CR questionnaire items

\begin{tabular}{|c|c|}
\hline CR Questionnaire (items 1-8) & n (\%) \\
\hline \multicolumn{2}{|l|}{ Education } \\
\hline Illiterate & $4(5.3)$ \\
\hline Can read and write (self-taught) & $8(10.7)$ \\
\hline Primary school ( $<6$ years) & $41(54.7)$ \\
\hline Elementary school (6-8 years) & $2(2.7)$ \\
\hline High school ( +9 years $)$ & $12(16.0)$ \\
\hline Higher education & $8(10.7)$ \\
\hline \multicolumn{2}{|l|}{ Parental education } \\
\hline No education & $12(16.0)$ \\
\hline Primary or elementary school & $57(76.0)$ \\
\hline High school or higher education & $6(8.0)$ \\
\hline \multicolumn{2}{|l|}{ Training courses } \\
\hline Without & $61(82.4)$ \\
\hline 1 or 2 & $8(10.8)$ \\
\hline 2 to 5 & $3(4.1)$ \\
\hline$\geq 6$ & $2(2.7)$ \\
\hline \multicolumn{2}{|l|}{ Occupation } \\
\hline Unskilled worker & $51(68.0)$ \\
\hline Skilled manual worker & $9(12.0)$ \\
\hline Skilled non-manual worker & $7(9.3)$ \\
\hline Professional & $7(9.3)$ \\
\hline Executive position & $1(1.3)$ \\
\hline \multicolumn{2}{|l|}{ Musical training } \\
\hline Does not play or listening & $73(97.3)$ \\
\hline Plays s little/often hears & $1(1.3)$ \\
\hline Formal training & $1(1.3)$ \\
\hline \multicolumn{2}{|l|}{ Languages } \\
\hline Only one language & $60(80.0)$ \\
\hline 2 languages & $14(18.7)$ \\
\hline$\geq 3$ languages & $1(1.3)$ \\
\hline \multicolumn{2}{|l|}{ Reading } \\
\hline Never & $38(50.7)$ \\
\hline Occasionally & $37(49.3)$ \\
\hline 2 to 5 books/year & $0(0)$ \\
\hline Over 10 books/year & $0(0)$ \\
\hline \multicolumn{2}{|l|}{ Intellectual games } \\
\hline Never or sometimes & $64(85.3)$ \\
\hline 1 to 5 times/month & $11(14.7)$ \\
\hline$\geq 6$ times/month & $0(0)$ \\
\hline
\end{tabular}

This questionnaire is a simple tool to evaluate the $\mathrm{CR}$ in Portuguese populations. CRQ is a questionnaire with good psychometric properties and may be a suitable instrument to measure CR in Portuguese populations.

\section{Discussion}

Our first objective was to assess CR using the CRQ and a set of variables (education, PLA, lifelong occupation) that inform CR. According to the CRI and CRQ scores, greater CR was found in the groups of patients with a higher educational level, a higher PLA score and more complex occupations. These results are in agreement with findings reported in previous studies that confirmed that variables describing lifetime experience (education, PLA, lifelong occupation) are the most commonly used proxies for CR. ${ }^{8,10,11,15}$

Our second objective was to develop a CR index. We selected the variables described in the literature as measures of CR (education, PLA and lifelong occupation) and we tested them for homogeneity of variance.

Our third objective was to validate a CR questionnaire. We found a close association between CRI and CRQ. The CRQ is a simple tool to evaluate CR in Portuguese populations. Our analysis revealed that the CRQ has high reliability and suitable content validity.

Our fourth objective was to examine the correlation between the different measures of CR (CRQ, CRI, education, PLA and lifelong occupation). We found that CR (CRQ and CRI) correlates with education, PLA and lifelong occupation, in agreement with findings reported in other studies. $8,9,16$

The main limitations of this study were its crosssectional design and its small sample size. Future longitudinal studies with larger samples should be conducted to address these limitations. 


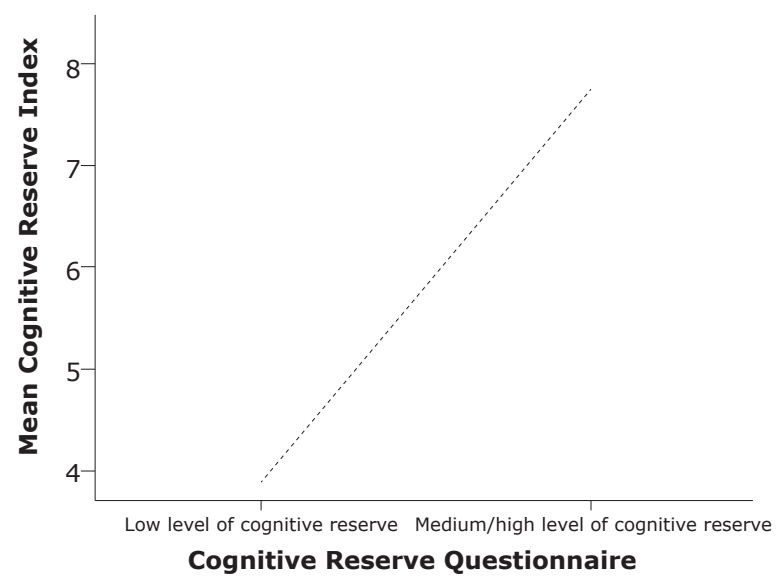

Figure 3 - Association between cognitive reserve index (CRI) and cognitive reserve questionnaire (CRQ) scores.

\section{Conclusion}

CR can be measured using the CRQ, CRI and a set of variables, such as education, PLA and lifelong occupation. Participants with a greater $\mathrm{CR}$ had higher scores on cognitive tests than the elderly with a lower CR. This study found an association between CR and education, occupation and PLA. The favorable psychometric properties of the Portuguese version of the CRQ recommend its use as an instrument to assess $C R$ in Portugal. Patients with a great $C R$ may benefit from it after the diagnosis of $A D$.

\section{References}

1. Berr C, Wancata J, Ritchie K. Prevalence of dementia in elderly in Europe. Eur Neuropsychopharmacol. 2005;15:463-71.

2. Cummings JL. Alzheimer's disease. N Engl J Med. 2004;351:56-67.

3. Jalbert JJ, Daiello LA, Lapane KL. Dementia of the Alzheimer type. Epidemiol Rev. 2008;30:15-34. Epub 2008 Jul 16.

4. Ziegler-Graham K, Brookmeyer R, Johnson E, Arrighi HM. Worldwide variation in the doubling time of Alzheimer's disease incidence rates. Alzheimers Dement. 2008;4:316-23.

5. Katzman R, Terry R, DeTeresa R, Brown T, Davies P, Fuld P, et al. Clinical, pathological, and neurochemical changes in dementia: a subgroup with preserved mental status and numerous neocortical plaques. Ann Neurol. 1988;23:138-44.

6. Siedlecki KL, Stern Y, Reuben A, Sacco RL, Elkind MS, Wright CB. Construct validity of cognitive reserve in a multiethnic cohort: The Northern Manhattan Study. J Int Neuropsychol Soc. 2009;15:558-69.

7. Scarmeas N, Albert SM, Manly JJ, Stern Y. Education and rates of cognitive decline in incident Alzheimer's disease. J Neurol Neurosurg Psychiatry. 2006;77:308-16.

8. Stern Y. Cognitive reserve in ageing and Alzheimer's disease. Lancet Neurol. 2012;11:1006-12.

9. Tucker AM, Stern Y. Cognitive reserve in aging. Curr Alzheimer Res. 2011;8:354-60.

10. Jones RN, Manly ], Glymour MM, Rentz DM, Jefferson AL, Stern Y. Conceptual and measurement challenges in research on cognitive reserve. J Int Neuropsychol Soc. 2011;17:593-601.
11. Zahodne LB, Manly JJ, Brickman AM, Siedlecki KL, Decarli C, Stern Y. Quantifying cognitive reserve in older adults by decomposing episodic memory variance: replication and extension. J Int Neuropsychol Soc. 2013;19:854-62. Epub 2013 Jul 18.

12. Albert MS, Jones K, Savage CR, Berkman L, Seeman T, Blazer D, et al. Predictors of cognitive change in older persons: MacArthur studies of successful aging. Psychol Aging. 1995;10:578-89.

13. Ganguli M, Ratcliff G, Huff FJ, Belle S, Kancel MJ, Fischer L, et al. Effects of age, gender, and education on cognitive tests in a rural elderly community sample: norms from the Monongahela Valley Independent Elders Survey. Neuroepidemiology. 1991;10:42-52.

14. James BD, Boyle PA, Buchman AS, Bennett DA. Relation of latelife social activity with incident disability among communitydwelling older adults. J Gerontol A Biol Sci Med Sci. 2011;66:46773. Epub 2011 Feb 7.

15. Sobral M, Paúl C. Education, leisure activities and cognitive and functional ability of Alzheimer's disease patients: a follow-up study. Dement Neuropsychol. 2013;7:181-89.

16. Scarmeas N, Stern Y. Cognitive reserve: implications for diagnosis and prevention of Alzheimer's disease. Curr Neurol Neurosci Rep. 2004; $4: 374-80$.

17. Fratiglioni L, Paillard-Borg S, Winblad B. An active and socially integrated lifestyle in late life might protect against dementia. Lancet Neurol. 2004;3:343-53.

18. Graves AB, Larson EB, Edland SD, Bowen JD, McCormick WC, McCurry SM, et al. Prevalence of dementia and its subtypes in the Japanese American population of King County, Washington state. The Kame Project. Am J Epidemiol. 1996;144:760-71.

19. Helmer C, Letenneur L, Rouch I, Richard-Harston S, BarbergerGateau P, Fabrigoule C, et al. Occupation during life and risk of dementia in French elderly community residents. J Neurol Neurosurg Psychiatry. 2001;71:303-9.

20. American Psychiatric Association. Diagnostic and Statistical Manual of Mental Disorders, 4th ed, text revision (DSM-IV-TR). Washington DC: American Psychiatric Association; 2000.

21. McKhann G, Drachman D, Folstein M, Katzman R, Price D, Stadlan EM. Clinical diagnosis of Alzheimer's disease: report of the NINCDS-ADRDA Work Group under the auspices of Department of Health and Human Services Task Force on Alzheimer's Disease. Neurology. 1984;34:939-44.

22. Rami L, Valls-Pedret C, Bartrés-Faz D, Caprile C, Solé-Padullés $C$, Castellvi $M$, et al. [Cognitive reserve questionnaire. Scores obtained in a healthy elderly population and in one with Alzheimer's disease]. Rev Neurol. 2011;52:195-201.

23. Folstein MF, Folstein SE, McHugh PR. "Mini-mental state". A practical method for grading the cognitive state of patients for the clinician. J Psychiatri Res. 1975;12:189-98.

24. Guerreiro MS, Botelho MA, Leitão O, Castro-Caldas A, Garcia C. Avaliação breve do estado mental. Adaptação Portuguesa do Mini Mental State Examination (MMSE) (Folstein, Folstein, \& McHugh, 1975). Lisboa: Grupo de Estudos de Envelhecimento Cerebral e Demências; 1994.

25. Hughes CP, Berg L, Danziger WL, Coben LA, Martin RL. A new clinical scale for the staging of dementia. $\mathrm{Br} J$ Psychiatry. 1982; 140:566-72

26. Mioshi E, Dawson K, Mitchell J, Arnold R, Hodges JR. The Addenbrooke's Cognitive Examination Revised (ACE-R): a brief cognitive test battery for dementia screening. Int J Geriatr Psychiatry. 2006;21:1078-85.

27. Graffar M. Une methode de classification sociale d'echantillons de population. Courier. 1956;6:455.

28. Instituto Nacional de Estatística. Classificação Nacional de Profissões 2010. Lisboa: INE; 2011.

29. Pestana MH, Gageiro JN. Análise de dados para Ciências Sociais: a complementaridade do SPSS, 5a ed. Portugal: Edições Sílabo, Lda; 2008.

\section{Correspondence:}

Margarida Sobral

Hospital de Magalhães Lemos

Rua do Professor Álvaro Rodrigues

4149-003 - Porto - Portugal

Tel./Fax: +351919254955 / +351226192469

E-mail: margaridasobral@hmlemos.min-saude.pt 